\title{
Separation of selected anesthetic drugs by nonaqueous capillary electrophoresis ${ }^{1}$
}

\author{
S. Cherkaoui and J.-L. Veuthey* \\ Laboratory of Pharmaceutical Analytical Chemistry, University of Geneva, \\ Bd d'Yvoy 20, 1211 Geneva 4, Switzerland
}

\begin{abstract}
The potential of nonaqueous capillary electrophoresis was investigated for the separation of selected anesthetic drugs. The effect of parameters, such as methanol-acetonitrile composition, temperature, apparent $\mathrm{pH}^{*}$ and ionic strength of the electrophoretic media on migration times and selectivity was discussed. The capillary electrophoresis separation of these drugs was compared in aqueous and nonaqueous media. The best separation was achieved with a fused silica capillary $(48.5 \mathrm{~cm}$ total length $\times 50 \mu \mathrm{m}$ I.D.), a buffer electrolyte solution composed of $25 \mathrm{mM}$ ammonium acetate in methanol, an applied voltage of $30 \mathrm{kV}$ and a temperature of $10{ }^{\circ} \mathrm{C}$. Replicate injections under the optimal nonaqueous conditions gave acceptable precision data for migration times and peak areas.
\end{abstract}

Key words. Nonaqueous capillary electrophoresis - drug analysis - local anesthetic.

\section{Introduction}

Local anesthetic agents play an important role in modern anesthesiology as they are widely used for local anesthesia as well as the management of major pain, either via central administration (spinal and epidural) or via peripheral administration $[1,2]$. Therefore, the determination of these anesthetics in biological fluids is necessary to understand their pharmacokinetics and toxicity after administration [3-5]. Furthermore, selective and robust analytical methods are required for the quality control of these agents in pharmaceutical preparations.

The determination of anesthetic drugs is generally performed by chromatographic techniques [6] such as gas chromatography (GC) [7] and high performance liquid chromatography (HPLC) [8-10]. Recently, particular attention has been directed towards the use of capillary electrophoresis (CE) for the analysis of pharmaceuticals [11]. Compared to chromatographic assays, the advantages of $\mathrm{CE}$ consist in a high resolution, an excellent separation efficiency, a rapid method development and small amount of sample required. Today, nonaqueous capillary electrophoresis (NACE) has become an active area of study [12-16], and has been successfully applied to the analysis of a large number of compounds including acidic [17-20] and basic [21-28] drugs, chiral compounds [29-31], ions [32,33] and preservatives [18]. Applying organic media instead of aqueous buffers presents a number of advantages. Indeed, the widespread physicochemical properties of organic solvents allow an improvement of the separation selectivity. In addition, several factors are available to manipulate the resolution, efficiency and migration time. Furthermore, the organic solvents extend the application range of $\mathrm{CE}$ to hydrophobic compounds as well as to substances prompted to degradation in water. Finally, organic solvents are appropriate media for the successful coupling of $\mathrm{CE}$ to a mass spectrometer detector [20,34-35].

This paper describes investigations on the potential of non aqueous CE for the analysis of nine local anesthetics. Factors affecting the separation of these anesthetic drugs, such as the nature and percentage of the organic solvent, the apparent $\mathrm{pH}^{*}$, the electrolyte composition and concentration, as well as the temperature, are also discussed.

\section{Experimental}

\section{Chemicals}

All anesthetic drugs were obtained in their hydrochloride form. Lidocaïne, mepivacaine, bupivacaïne, cinchocaine, procaine, prilocaine and chloroprocaïne were supplied by Sintetica (Mendrisio, Switzerland). Cocaine and ketamine were purchased from Fluka (Buchs, Switzerland). All chemicals such as acetic acid, trifluoroacetic acid, ammonium acetate, tris(hydroxymethyl)aminomethane (Tris) and phosphoric acid were obtained from Fluka (Buchs, Switzerland), while analytical grade methanol and acetonitrile were purchased from Romil (Kölliken, Switzerland).

\section{Instrumentation and electrophoretic procedure}

$\mathrm{CE}$ data were generated by means of a Hewlett-Packard (Waldbronn, Germany) HP ${ }^{3 \mathrm{D}} \mathrm{CE}$ capillary electrophoresis

1. This work was presented at the chromatographic symposium SEP'99 in Lyon (France), March 31-April 2, 1999.

* Correspondence and reprints.

Received March 26, 1999; revised October 01, 1999; accepted October 05, 1999. 
system equipped with an on-column diode-array detector, an autosampler and a power supply able to deliver up to $30 \mathrm{kV}$. The total capillary length (Hewlett-Packard) was $48.5 \mathrm{~cm}$, while the length to the detector was $40 \mathrm{~cm}$, with a $50 \mu \mathrm{m}$ internal diameter. An alignment interface, containing an optical slit matched to the internal diameter, was used and the detection wavelength was set at $200 \mathrm{~nm}$ with a bandwidth of $10 \mathrm{~nm}$. A CE Chemstation (Hewlett-Packard) was used for instrument control, data acquisition and data handling.

All experiments were carried out in cationic mode (anode at the inlet and cathode at the outlet). The capillary was thermostated at $10{ }^{\circ} \mathrm{C}$. Unless otherwise stated, a constant voltage of $30 \mathrm{kV}$, with an initial ramping of $500 \mathrm{Vs}^{-1}$, was applied during analysis. Sample injection (6 nl) was achieved using the pressure mode for $8 \mathrm{~s}$ at $25 \mathrm{mbar}$. The migration order was determined by injection of individual anesthetic drugs.

At the beginning of each day, the capillary was rinsed successively with $0.1 \mathrm{M}$ sodium hydroxide, followed by water and acetonitrile for $5 \mathrm{~min}$ each. This flushing procedure is expected to remove any trace of water from the capillary. Between analyses, the capillary was flushed with the running buffer for $3.5 \mathrm{~min}$. As the electrolysis of a solution can alter the running buffer and subsequently change the electroosmotic flow (EOF), the separation buffer was replaced between injections. When not in use, the capillary was washed with acetonitrile, water and then dry stored.

\section{Buffer and sample preparation}

The non-aqueous buffer was prepared by mixing the appropriate amount of ammonium acetate in methanol with other components such as acetonitrile, acetic acid or trifluoroacetic acid (TFA). Before use, the electrolyte solutions were filtered through a $0.20 \mu \mathrm{m}$ microfilter (Supelco, Bellefonte, PA, USA). The apparent $\mathrm{pH}^{*}$ value was determined by a pH-meter equipped with a combined glasscalomel electrode. The electrode was calibrated using standard aqueous buffers. Stock standard solutions of the anesthetic drugs were prepared by dissolving each compound in methanol in order to give a concentration of $1 \mathrm{mg} \mathrm{mL} \mathrm{m}^{-1}$. The anesthetic mixture was prepared by dissolution of individual compounds in methanol.

\section{Results and discussion}

Most of the reported CE separations of pharmaceutical drugs are performed in aqueous media. In the case of basic compounds, separations are generally achieved using acidic electrolytes. In such buffers, the migration of each analyte is mainly governed by its electrophoretic mobility since the electroosmotic flow is negligible. The electrophoretic mobility depends on the molecular size (or molecular mass), shape and net charge of the analyte. Thus, in the absence of a modifier, the selectivity in CZE mode is mainly dictated by the structure of the analyte and the nature of the surrounding environmental conditions. Since the investigated anesthetics are basic compounds (Tab. I) which exhibit the same charge at acidic $\mathrm{pH}$, the main factors controlling the electrophoretic mobility of a given solute are its size and shape. While the former depends on both the molecular mass and the resulting degree of solvation of the ionic species in solution, the latter is mainly determined by the molecular geometry. Thus, some selectivity variations can be expected when using water or a mixture of organic solvent such as methanol-acetonitrile.

\section{Aqueous CE}

The first CE experiments were performed in aqueous media. As shown in figure 1, using a $50 \mathrm{mM}$ Tris-phosphate buffer at $\mathrm{pH} 2.5$ resulted in the baseline separation of 8 anesthetics in less than 12 min. However, under the selected conditions, mepivacaine comigrated with lidocaine. As shown in figure 1, the migration order of the investigated drugs was not directly related to charge to mass ratio. The observed behavior can be attributed to different solvation degree of the protonated species as well as to their molecular geometry. It has to be noted that these compounds migrated in two distinct groups consisting of the ester type drugs (cocaine, procaine, chloroprocaine), followed by the amide type drugs (prilocaine, bupivacaine, mepivacaine). Moreover, for compounds possessing a similar structure such as procainechloroprocaine and bupivacaine-mepivacaine-lidocaine, the migration order is function of the charge to mass ratio.

\section{Nonaqueous CE}

In previous works $[27,28]$ concerning the application of non aqueous CE to the analysis of drugs such as tropane alkaloids and amphetamines, it was demonstrated that resolution, efficiency and migration times were critically affected by the nature of the organic solvent, the electrolyte composition, its concentration and the temperature. Thus, these factors were systematically investigated for the separation of anesthetic drugs.

In the literature, because of their different physical and chemical properties (viscosity, dielectric constant, polarity, auto-protolysis constant, etc.), methanol and acetonitrile are the most frequently used solvents for NACE [12,13]. In particular, methanol-acetonitrile mixture containing $25 \mathrm{mM}$ ammonium acetate and $1 \mathrm{M}$ acetic acid is considered to be the appropriate electrolyte solution for the separation of a large variety of basic drugs [21]. Thus, preliminary experiments were carried out using this electrolyte solution. Unfortunately, the complete separation of the nine anesthetics was not achieved (data not shown). Acetic acid was therefore replaced by trifluoroacetic acid (TFA) which presents a low UV absorbance, is more volatile and can act as an ion pairing agent. Indeed, as already reported, the addition of TFA was found beneficial as it manipulates the selectivity of very closely related compounds, such as hyoscyamine and its positional isomer littorine, as well as those of amphetamine derivatives [27, 28]. 
Table I. Structure and $\mathrm{pK}$ values (in water) of the investigated anesthesic drugs.

Ester type

Cocaine (1)<smiles>COC(=O)C1C(OC(=O)c2ccccc2)CC2CCC1N2C</smiles>

Procaine (2)<smiles>C=C(CCCC(C)C)c1ccc(Br)cc1</smiles>

Chloroprocaine (3)<smiles>CC(C)CCCC(=O)c1ccc(Br)cc1I</smiles>

Prilocaine (4)

Amide type<smiles>CC(C(=O)C(C)C(C)C)c1ccccc1I</smiles>

Cinchocaine (5)<smiles>CCCCCCc1cc(C(=O)C(C)CCC(C)C)c2ccccc2c1</smiles>

Bupivacaine (6)<smiles>Cc1cccc(C)c1C(C)C(=O)C1CCCCC1C</smiles>

Lidocaine (8)<smiles>Cc1cccc(C)c1C(C)C(=O)CC(C)C</smiles>

Ketamine (9)

General anesthetic<smiles>C=C1CCCCC1(CC)c1ccccc1I</smiles> 


\section{Original articles}

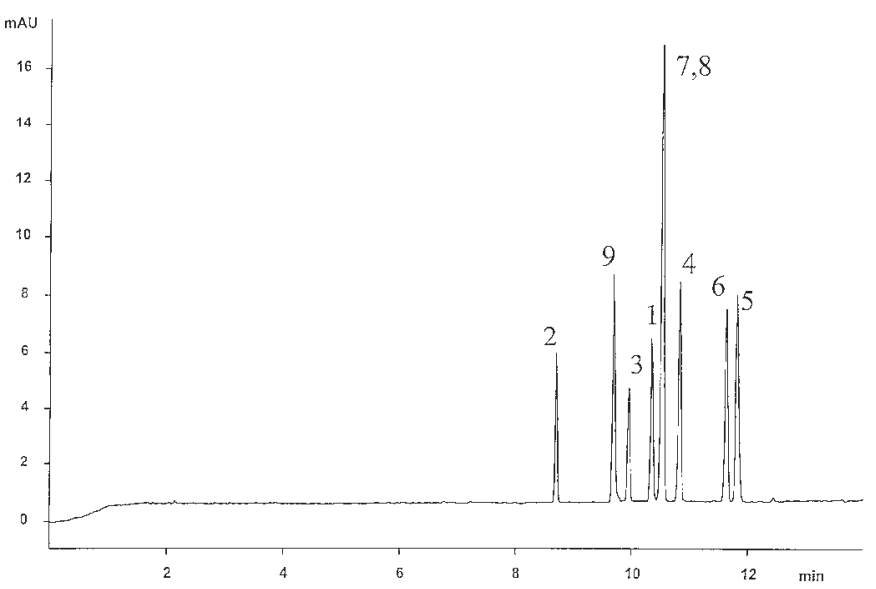

Fig. 1. CE separation of anesthetic drugs using aqueous media. Electrophoretic buffer: $50 \mathrm{mM}$ tris-phosphate $(\mathrm{pH} 2.5)$ in water. Applied voltage: $30 \mathrm{kV}$. Temperature $20{ }^{\circ} \mathrm{C}$. For peak identification, see table I.

\section{Methanol-acetonitrile composition}

By keeping constant the electrolyte composition $(50 \mathrm{mM}$ ammonium acetate and $100 \mathrm{mM}$ TFA), the influence of the methanol percentage in acetonitrile was investigated. As shown in figure 2 , migration time, reported as a function of the methanol percentage in acetonitrile, presents a minimum value at $20 \%$ methanol. This behavior is mainly due to the concomitant changes of viscosity $(\eta)$ and dielectric constant ( $\varepsilon$ ) of the electrolyte solution. Indeed, the $\varepsilon / \eta$ ratio is maximum at $20 \% \mathrm{MeOH}$, and since the electrophoretic mobility is directly proportional to $\varepsilon / \eta$ ratio, this mixture exhibited shorter migration times. Moreover, depending on the composition of the organic solvent, different selectivities were achieved (Fig. 2). Thus, in presence of $100 \mathrm{mM}$ TFA and $50 \mathrm{mM}$ ammonium acetate, the best separation of the anesthetic drugs was obtained at a methanol percentage higher than $80 \%$. Finally, a $100 \%$ methanolic solution containing TFA and ammonium acetate was selected for subsequent investigations.

Since the studied drugs are fully charged at acidic $\mathrm{pH}^{*}$, the changes in selectivity are certainly due to solvation differences, as reported in the literature $[12,13]$. Moreover, some inversions of the migration order occurred when acetic acid was used instead of TFA (Fig. 3a, b) which means that, in methanolic solutions, TFA may act not only as an acidic agent but also as an ion-pairing agent for cationic drugs. For example, in presence of TFA, procaine and lidocaine were baseline resolved while they comigrated with acetic acid. The opposite behavior was observed for bupivacaine and prilocaine. In addition, mepivacaine migrated at the third position in acetic buffer, but its mobility was reduced in presence of TFA. Therefore, the selectivity differences observed between aqueous and nonaqueous media can be

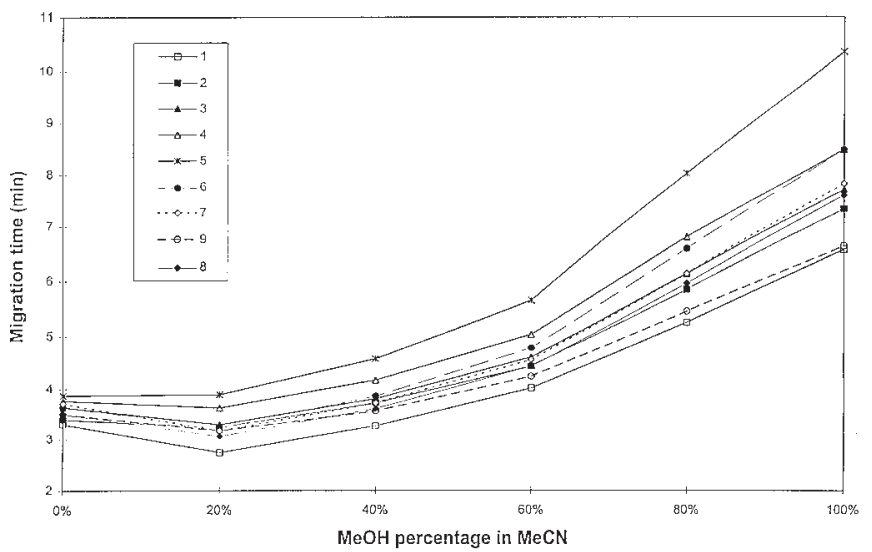

Fig. 2. Effect of methanol percentage in $\mathrm{MeOH}-\mathrm{MeCN}$ mixture on migration times of the selected anesthetic drugs. Electrophoretic medium: $100 \mathrm{mM}$ TFA and $50 \mathrm{mM}$ ammonium acetate in the organic solvent. Applied voltage: $25 \mathrm{kV}$. Temperature $10{ }^{\circ} \mathrm{C}$. For peak identification, see table I.

probably explained by solvation changes of the investigated analytes and/or ion-pairs formation in the presence of TFA.

\section{Temperature}

Temperature was reported to have a great influence on selectivity in nonaqueous media [20, 23]. Therefore, The effect of this parameter (from 10 to $40{ }^{\circ} \mathrm{C}$ ) on the separation of the anesthetic drugs was studied. As temperature increased, migration times decreased, as a result of viscosity decrease, without any effect on the migration order (data not shown). However, the best resolution was obtained at the lowest studied temperature (i.e. $10{ }^{\circ} \mathrm{C}$ ).

\section{Electrolyte solution}

As in aqueous $\mathrm{CE}$, the apparent $\mathrm{pH}^{*}$ plays an important role during method optimization. Indeed, it is well known that resolutions are best achieved when the working $\mathrm{pH}$ is close to the $\mathrm{pKa}$ values of investigated compounds. Working in organic solvents can modify the acid-base properties to varying extents, depending on the nature of the investigated compounds as well as on the solvent employed. Thus, different electrolyte solutions (Tab. II) were prepared in order to investigate the apparent $\mathrm{pH}^{*}$ effect in a large range. Figure 4 shows that above $\mathrm{pH}^{*} 7$, a complete separation of the nine investigated anesthetics was achieved and also that the $\mathrm{pH}^{*}$ modified the selectivity. The changes of migration order, observed at apparent $\mathrm{pH}^{*}$ higher than 6 , indicate that most of the studied analytes are partially deprotonated at this $\mathrm{pH}^{*}$, which results in a better discrimination on the basis of charge to mass ratios. Nevertheless, the changes in $\mathrm{pH}^{*}$ are not the only explanation for the migration time behavior as the variations in the ionic strength of the selected media must also be considered. 

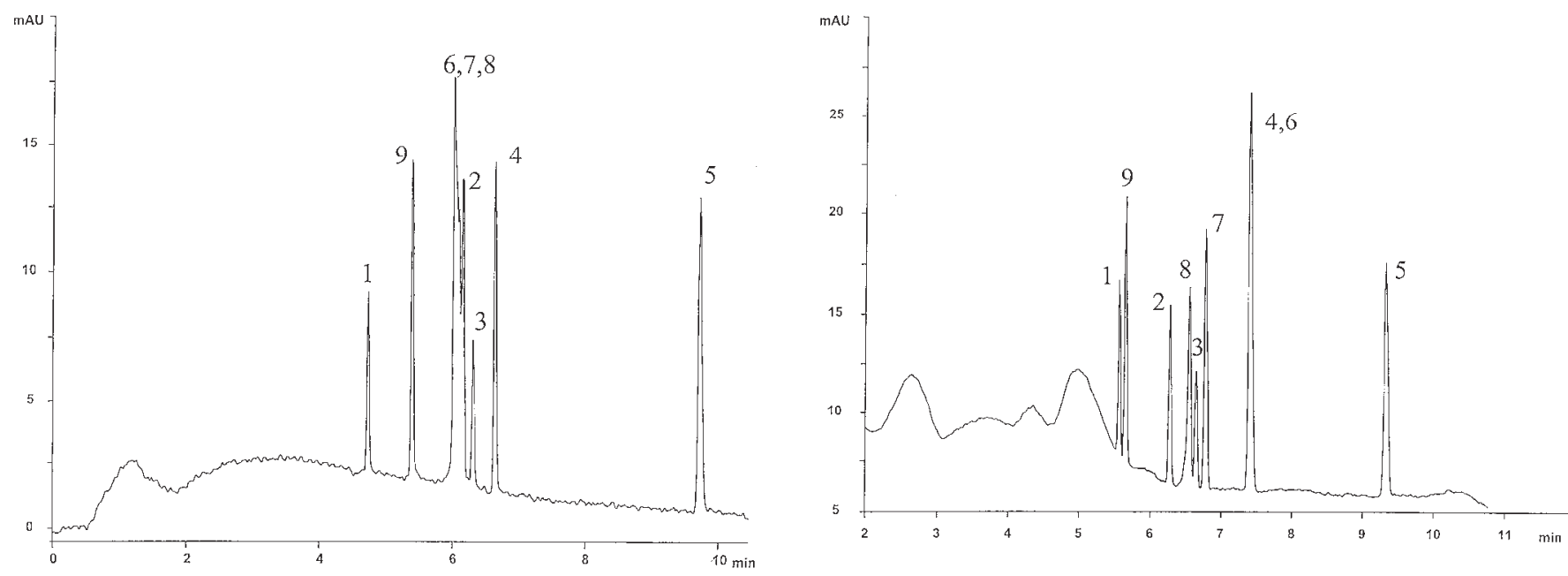

Fig. 3. Electropherograms of selected anesthetic drugs obtained by nonaqueous capillary electrophoresis. Electrophoretic medium: A) Pure methanol containing $50 \mathrm{mM}$ ammonium acetate and $100 \mathrm{mM}$ TFA ( $\mathrm{pH}^{*}$ 2), generated current: $\left.38 \mu \mathrm{A}, \mathrm{B}\right)$ Pure methanol containing $50 \mathrm{mM}$ ammonium acetate and $1 \mathrm{M}$ acetic acid $\left(\mathrm{pH}^{*}\right.$ 5), generated current: $29 \mu \mathrm{A}$. Applied voltage: $30 \mathrm{kV}$. Temperature $10{ }^{\circ} \mathrm{C}$. For peak identification, see table I.

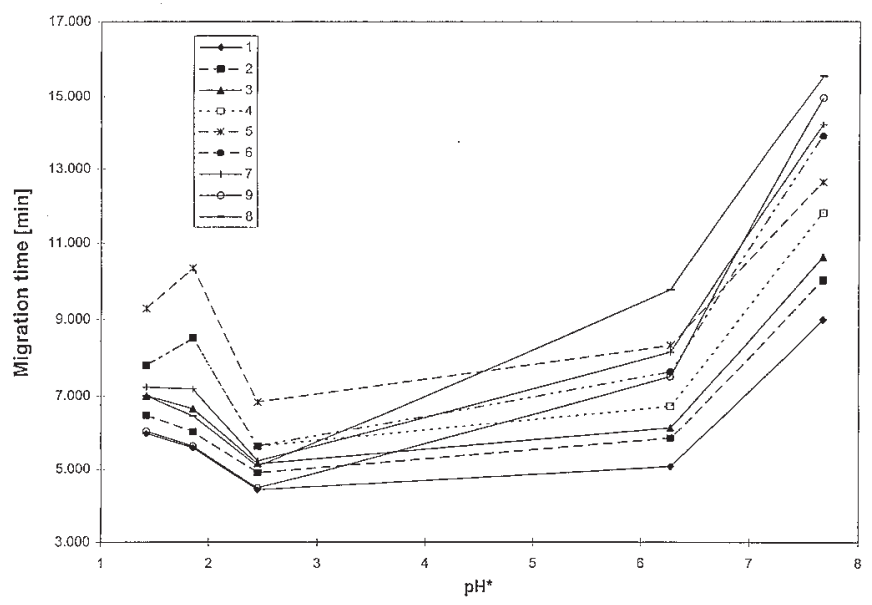

Fig. 4. Migration times of the investigated drugs versus the apparent $\mathrm{pH}^{*}$ by using various electrolytes in methanol according to table II. Applied voltage: $30 \mathrm{kV}$. Temperature $10^{\circ} \mathrm{C}$. For peak identification, see table I.

The electrolyte concentration is also an important parameter. Thus, the ammonium acetate concentration was investigated between 25 and $100 \mathrm{mM}$. As shown in figure 5, increasing the ammonium acetate concentration to $50 \mathrm{mM}$, results in resolution improvement at the expense of migration times increase, because of the electroosmotic flow decrease. It is noteworthy that a higher ionic strength concentration results in bupivacaïne and mepivacaine co-migration. Thus, using a $50 \mathrm{~mm}$ inner diameter fused silica capillary, with methanol containing $25 \mathrm{mM}$ ammonium acetate,

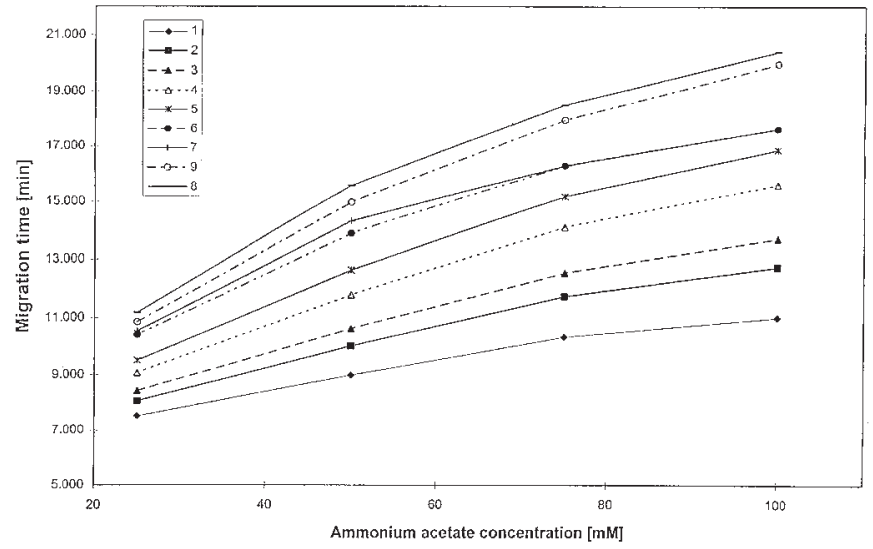

Fig. 5. Effect of ammonium acetate concentration on the migration times of the selected anesthetic drugs. Electrophoretic medium: Pure methanol containing increasing amount of ammonium acetate. Applied voltage: $30 \mathrm{kV}(\mathrm{i}=17 \mu \mathrm{A})$. Temperature $10{ }^{\circ} \mathrm{C}$. For peak identification, see table I.

Table II. Electrophoretic media with apparent $\mathrm{pH}^{*}$.

Electrolyte composition

Apparent $p H^{*}$

$0 \mathrm{M}$ TFA and $50 \mathrm{mM}$ ammonium acetate in methanol 7.67 $25 \mathrm{mM}$ TFA and $50 \mathrm{mM}$ ammonium acetate in methanol 6.27 $50 \mathrm{mM}$ TFA and $50 \mathrm{mM}$ ammonium acetate in methanol 2.45 $100 \mathrm{mM}$ TFA and $50 \mathrm{mM}$ ammonium acetate in methanol 2.40 $0.5 \mathrm{M}$ TFA and $50 \mathrm{mM}$ ammonium acetate in methanol 1.85 $1 \mathrm{M}$ TFA and $50 \mathrm{mM}$ ammonium acetate in methanol 1.42 


\section{Original articles}

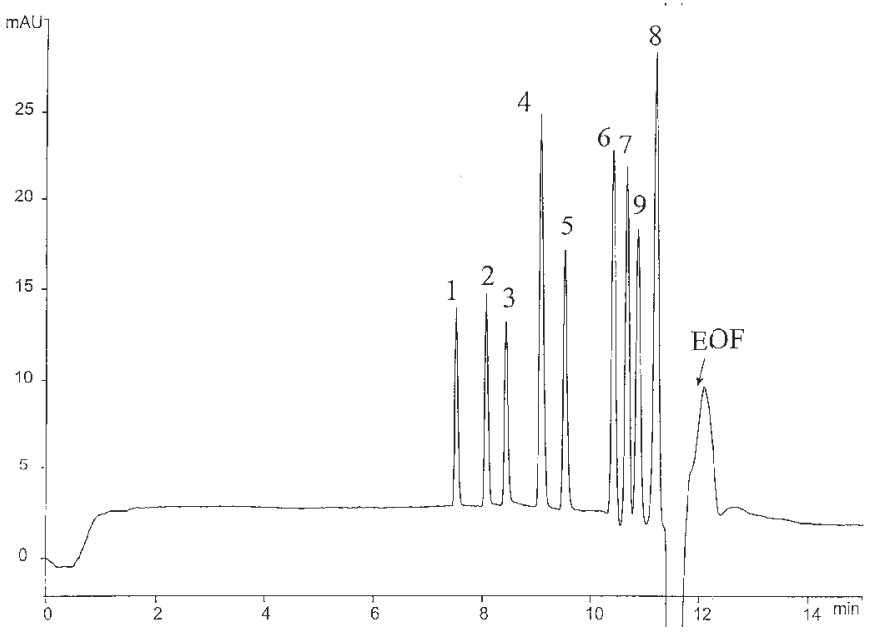

Fig. 6. Typical electropherogram of selected anesthetic drugs obtained under non aqueous capillary electrophoresis conditions. Electrophoretic medium: Pure methanol containing $25 \mathrm{mM}$ ammonium acetate. Applied voltage: $30 \mathrm{kV}$. Temperature $10{ }^{\circ} \mathrm{C}$. For peak identification, see table I.

yielded the best compromise in terms of analysis time, selectivity and separation efficiency. Under the selected conditions, all the investigated compounds migrated before the electroosmotic flow, as illustrated in figure 6 .

\section{Repeatability}

The volatile buffer used as electrophoretic medium is proned to evaporation during the electrophoretic separation. This phenomenon may have a detrimental effect on the migration time repeatability as well as on the quantitative performances of the method developed. Thus, in order to assess the precision of the method, replicate injections $(n=6)$ of the anesthetic mixture were carried out. As shown in table III, relative standard deviation (R.S.D.) values for repeatability are better than $1 \%$ and $2.6 \%$ for migration times and peak areas, respectively. The use of air tight vials to avoid solvent evaporation and the appropriate control of the separation temperature were necessary to achieve this good data.

\section{Conclusion}

A selective nonaqueous capillary electrophoresis method was developed for the separation of nine anesthetic drugs. Compared to aqueous media and because of the modification of the analyte solvation and dissociation constant, as well as of the concomitant variation of viscosity and dielectric constant of the electrophoretic medium, different selectivities were achieved with various methanol-acetonitrile mixtures. Furthermore, the apparent $\mathrm{pH}^{*}$ and the ionic strength of the separation buffer had a critical effect on the separation. With a methanolic solution containing $25 \mathrm{mM}$
Table III. Precision of migration time and peak area of the tested anesthetic drugs.

\begin{tabular}{lcc}
\hline Compound & \multicolumn{2}{c}{ Mean $\pm S D(R S D)^{*}$} \\
& $\begin{array}{c}\text { Migration time } \\
(\text { min })\end{array}$ & $\begin{array}{c}\text { Peak area } \\
\text { Arbitrary units }\end{array}$ \\
\hline $\mathbf{1}$ & $7.291 \pm 0.040(0.55)$ & $42.892 \pm 0.967(2.26)$ \\
$\mathbf{2}$ & $7.810 \pm 0.047(0.60)$ & $49.525 \pm 1.150(2.32)$ \\
$\mathbf{3}$ & $8.160 \pm 0.052(0.64)$ & $44.192 \pm 0.974(2.21)$ \\
$\mathbf{4}$ & $8.798 \pm 0.063(0.71)$ & $113.318 \pm 2.402(2.12)$ \\
$\mathbf{5}$ & $9.209 \pm 0.069(0.75)$ & $68.784 \pm 1.582(2.30)$ \\
$\mathbf{6}$ & $10.068 \pm 0.085(0.84)$ & $102.213 \pm 2.560(2.51)$ \\
$\mathbf{7}$ & $10.318 \pm 0.091(0.88)$ & $93.762 \pm 1.115(1.19)$ \\
$\mathbf{9}$ & $10.503 \pm 0.095(0.91)$ & $84.117 \pm 2.087(2.48)$ \\
$\mathbf{8}$ & $10.819 \pm 0.103(0.95)$ & $154.258 \pm 0.433(2.59)$ \\
\hline
\end{tabular}

S.D.: standard deviation

R.S.D.: relative standard deviation.

ammonium acetate, nonaqueous $\mathrm{CE}$ offers a suitable and rapid method for the simultaneous analysis of the 9 investigated anesthetics. Finally, due to its volatility, the described nonaqueous medium is appropriate for the coupling of $\mathrm{CE}$ to MS.

\section{References}

1. Levinson, G. In Clinical procedures in Anesthesia and Intensive Care; Lippincott, J.B., Ed.; Benumof J.L., Philadelphia, PA; 1992, Chapter 31, p 645.

2. Howell, H.B. In Clinical procedures in Anesthesia and Intensive Care; Lippincott, J.B., Ed.; Benumof J.L., Philadelphia, PA; 1992, Chapter 31, p 645.

3. Lindberg, R. L. P.; Pihlajamaki, K. K. J. Chromatogr. 1984, 309, 369-374.

4. Kastrissios, H.; Hung, M. F.; Triggs, E. J. J. Chromatogr. 1992, 577, 103-107.

5. Le Guevello, Le Corre, P.; Chevanne, F.; Le Verge, R. J. Chromatogr. 1993, 622, 284-290.

6. Florey, K. In Analytical Profiles of Drugs; Florey, K. Ed.; Academic Press, New York; 1991, Vol. 14, 15, 18 and 19.

7. Lesko, L.J.; Ericson, J.; Ostheimer, G.; Marion, A. J. Chromatogr. 1980, 182, 226-231.

8. Gill, R.; Abbott, R. W.; Moffat, A. C. J. Chromatogr. 1984, 301, 155-163.

9. Escuder-Gilabert, L.; Sagrado, S.; Villanueva-Camanãs, R. M.; Medina-Hernandez, M. J. Chromatographia 1999, 49, 85-90.

10. Brun, F.; Veuthey, J.-L. J. Pharm. Biomed. Anal. 1996, 14, 1251-1259.

11. Grossman, P.D. In Capillary Electrophoresis Theory and Practice; Colburn, J. (Eds.), Academic Press; San Diego, 1992.

12. Valko, I.E.; Siren, H.; Riekkola, M.L. LC-GC Int. 1997, 3, 190-196.

13. Hansen, S.H.; Tjornelund, J.; Bjornsdottir, I. Trends Anal. Chem. 1996, 15, 175-180.

14. Sarmini, K.; Kenndler, E. J. Chromatogr. A 1997, 792, 3-11. 
15. Riekkola, M. L.; Wiedmer, S. K.; Valko, I. E.; Sirem, H. J. Chromatogr. A 1997, 792, 13-35.

16. Bjornsdottir, I.; Tjornelund, J.; Hansen, S.H. Electrophoresis 1998, 19, 2179-2186.

17. Salimi-Moosavi, N.; Cassidy, R.M. Anal. Chem. 1995, 67, 1067-1073.

18. Altria, K.D.; Bryant, S.M. Chromatographia 1997, 46, 122130.

19. Jansson, M.; Roerrade, J. Chromatographia 1995, 40, 163169.

20. Hansen, S.H.; Jensen, M. E.; Bjornsdottir, I. J. Pharm. Biomed. Anal. 1998, 17, 1155-1160.

21. Leung, G.N.W.; Tang, H.P.O.; Tso, T.S.C.; Wan, T.S.M.; J. Chromatogr. A 1996, 738, 141-154.

22. Bjornsdottir, I.; Hansen, S.H.; J. Chromatogr. A 1995, 711, 313-322.

23. Bjornsdottir, I.; Hansen, S.H.; J. Pharm. Biomed. Analysis 1995, 13, 1473-1481.

24. Wenzhe, L. U.; Poon, G.K.; Carmichael, P.L.; Cole, R.B. Anal.Chem. 1996, 68, 668-674.
25. Tjornelund, J.; Hansen, S.H. Chromatographia 1997, 44, 5-9.

26. Tjornelund, J.; Hansen, S.H. J. Chromatogr. A 1995, 779, 235243.

27. Cherkaoui, S.; Mateus, L.; Christen, P.; Veuthey, J.-L. Chromatographia 1999, 49, 54-60.

28. Cherkaoui, S.; Varesio, E.; Christen, P.; Veuthey, J.-L. Electrophoresis 1999, 19, 2900-2906.

29. Wang, F.; Khaledi, M. G. Anal. Chem. 1996, 68, 3460-3467.

30. Vincent J. B.; Vigh, G. J. Chromatogr. A 1998, 817, 121-128.

31. Wang, F.; Khaledi, M. G. J. Chromatogr. A 1998, 816, 233241.

32. Altria, K.D.; Wallberg, M.; Westerlund, D. J. Chromatogr. B 1999, 714, 99-104.

33. Tjornelund, J.; Bazzanella, A.; Lochmann, H.; Bächmann, K. J. Chromatogr. A 1998, 811, 211-217.

34. Tomlinson, A. J.; Benson, L. M.; Naylor, S. LC-GC Int. 1995, 8(4), 210-216.

35. Tomlinson, A. J.; Benson, L. M.; Naylor, S. J. Capil. Electrophor. 1994, 1(2), 127-135. 